\title{
RELAÇÃO ENTRE OS NUTRIENTES APLICADOS NA CULTURA COM A COMPOSIÇÃO QUÍMICA E PERDAS DURANTE O ARMAZENAMENTO DE BULBOS DE CEBOLA
}

\author{
Lauri João Marconatto ${ }^{1}$, Leandro Luiz Marcuzzo ${ }^{1}$ \\ ${ }^{1}$ Instituto Federal Catarinense - Campus Rio do Sul, Rio do Sul, 89160-202, Santa Catarina, Brasil
}

Autor para correspondência: Lauri João Marconatto; e-mail: lauri.marconatto@ifc.edu.br

Recebido: 03/10/2020, Aceito: 21/12/2020

\begin{abstract}
Resumo
A cebola é um produto agrícola com alta perecibilidade, principalmente, pela grande presença de água no bulbo. No entanto, na sua composição, estão presentes substâncias que podem garantir sua preservação por longo tempo de armazenagem, tais como: açúcares; acidez; metabólicos secundários; teor de nutrientes; e entre outros. Esta composição é consequência de muitos fatores, entre os quais, características da cultivar, práticas de cultivo, nutrição, clima, sanidade e processo de cura, que acabam definindo a composição do bulbo. Este trabalho buscou correlacionar duas classes e cultivares com as adubações, composição e as perdas por desidratação, apodrecimento e brotamento durante a armazenagem. Foram coletados bulbos classes 3 e 4 das cultivares Crioula e Bola Precoce, nas propriedades de 27 agricultores e armazenados por 140 dias num mesmo local e identificados os procedimentos de adubação. Ao final do período de armazenagem, foi determinada a composição mineral das amostras. Foi avaliada a correlação entre adubações, classes, cultivares, composição e perdas. Entre os resultados, a cv. Crioula apresentou maior susceptibilidade ao brotamento que a cultivar Bola Precoce. Quanto mais ácida for a cebola maior a brotação. $\mathrm{O}$ aumento do teor de $\mathrm{Zn}$ no bulbo favorece ao brotamento e o excesso de adubação com Zn deve ser evitado para armazenagem. A adubação de cobertura com potássio interferiu de forma positiva no teor de Sólidos Solúveis Totais e negativa ao teor de manganês na composição e as três perdas têm correlação negativa com Sólidos Solúveis Totais. Maior teor de K no bulbo tem correlação positiva fraca com as três perdas. As perdas diminuem com o aumento dos Sólidos Solúveis Totais.
\end{abstract}

Palavras-chave: Allium cepa L., adubação, pós-colheita

\section{RELATIONSHIP BETWEEN NUTRIENTS APPLIED IN THE CULTURE AND CHEMICAL COMPOSITION AND LOSSES DURING STORAGE OF ONION BULBS}

\begin{abstract}
The onion is an agricultural product with high perishability, mainly due to the large presence of water in the bulb. However, in its composition, are present substances that can ensure its preservation for long storage time, such as: sugars; acidity; secondary metabolic; nutrient content; and among others. This composition is a consequence of many factors, among which, characteristics of the cultivar, cultivation practices, nutrition, climate, sanity and healing process, which end up defining the composition of the bulb. This work sought to correlate two classes and cultivars with fertilization, composition and losses due to dehydration, rot and sprouting during storage. Bulbs Class 3 and 4 bulbs were collected from to cultivars Crioula and Bola Precoce in farms of 27 farmers and stored for 140 days in a single site and your fertilization procedures were identified. At the end of the storage period, the mineral composition of the samples was determined. The correlation between fertilizations, classes, cultivars, composition, and losses was evaluated. Among the results, cv. Crioula presented greater susceptibility to sprouting than the Precocious Ball cultivar. The more acid the onion is the larger the bud. The increase of $\mathrm{Zn}$ content in the bulb favors sprouting and the excess of $\mathrm{Zn}$ fertilization should be avoided for storage. Fertilization after planting with potassium positively interferes with the content of total soluble solids and negative to the manganese content in the composition and the three losses have negative correlation with total soluble solids. Higher K content in the bulb has a weak positive correlation with the three losses. Losses decrease with the increase of the Total Soluble Solids.
\end{abstract}

Keywords: Allium cepa L, fertilizing, post-harvest. 


\section{Introdução}

A cebola (Allium cepa L.) como as demais hortaliças, é um produto altamente perecível, que determina importantes perdas pós-colheitas se não forem observadas as devidas técnicas de produção como o ponto de colheita, adequada cura, eficiente sistema de armazenamento, cuidados no manuseio e no transporte (MORRETTI; DURIGAM, 2002).

No que tange à composição química, a presença de metabólitos secundários e a estrutura de revestimento do bulbo, entre outros fatores, interferem nas condições de conservação, na qualidade final do bulbo e, principalmente, no crescimento microbiológico. Essa composição modifica-se no decorrer do tempo, uma vez que são estruturas vivas, que mesmo depois de colhidos, curados e armazenados, continuam seus processos fisiológicos, verificando que a composição dos alimentos tem relação direta com a sua conservação (BOEING, 2002).

Os açúcares solúveis presentes no suco ou polpa são responsáveis pelo sabor característico de cada hortaliça, em que o grau de "doçura" é função do aumento da concentração de sólidos. A Acidez Total Titulável (ATT) relacionada com teores dos ácidos orgânicos presentes no suco ou polpa, aliada aos teores de Sólidos Solúveis Totais (SST), sendo uma característica importante para se avaliar a qualidade pós-colheita das hortaliças (CHITARRA; CHITARRA, 1990).

O potássio é o nutriente que tem grande importância juntamente com o nitrogênio para plantas que armazenam reservas em estruturas especializadas como o bulbo da cebola (LOUÉ, 1978). Esse nutriente caracteriza por ser um ativador de grupos de enzimas vegetais que controlam as reações, as quais ocorrem na célula, principalmente, nas sintetases, desidrogenases, oxiredutases, quinases e transferases, estando estreitamente relacionadas com os processos de assimilação do gás carbônico e de nitrogênio na formação de compostos nitrogenados e na síntese, translocação e armazenamento de açúcares (MALAVOLTA, 1980; MALAVOLTA; CROCOMO, 1982; CHAVES; PEREIRA, 1985).

Os micronutrientes são fundamentais para o crescimento e o desenvolvimento das plantas, o B, agindo como constituintes das paredes celulares, juntamente com o Zn também das membranas celulares, das quais são constituintes de diversas enzimas que atuam nos processos de respiração, controle hormonal e síntese de proteínas e afeta a síntese e conservação de auxinas, hormônios vegetais envolvidos no crescimento, o Fe, Mn, $\mathrm{Cu}$ e Ni como constituintes de enzimas, o Mn e $\mathrm{Zn}$ como ativadores de enzimas,o Fe, $\mathrm{Cu}, \mathrm{Mn}$ e $\mathrm{Cl}$ na fotossíntese, o Mn, Zn e Mo conferem resistência contra estresses bióticos e abióticos, incluindo pragas e doenças (KIRKBY; RÖMHELD, 2007).

O objetivo deste trabalho foi identificar interações entre a aplicação de fertilizantes, composição mineral, acidez e sólidos solúveis com as perdas na armazenagem de duas classes de duas cultivares cebola na região do Alto Vale do Itajaí, Santa Catarina.

\section{Material e Métodos}

O trabalho foi realizado a partir do armazenamento de 140 dias de bulbos de cebola com diâmetros entre 51 e $70 \mathrm{~mm}$ (classe 3) com peso inicial médio de $140 \mathrm{~g}$ e entre 71 e $90 \mathrm{~mm}$ (classe 4) peso inicial médio de $197 \mathrm{~g}$ das cultivares 'Epagri 362' (Crioula) e 'Empasc 352' (Bola Precoce), coletados em diferentes propriedades nos municípios de Alfredo Wagner, Chapadão do Lajeado, Imbuia, Ituporanga, Leoberto Leal e Vidal Ramos, todos localizados na região do Alto Vale do Itajaí, de acordo com a Figura 1, no estado de Santa Catarina, durante a primeira quinzena de 2015.

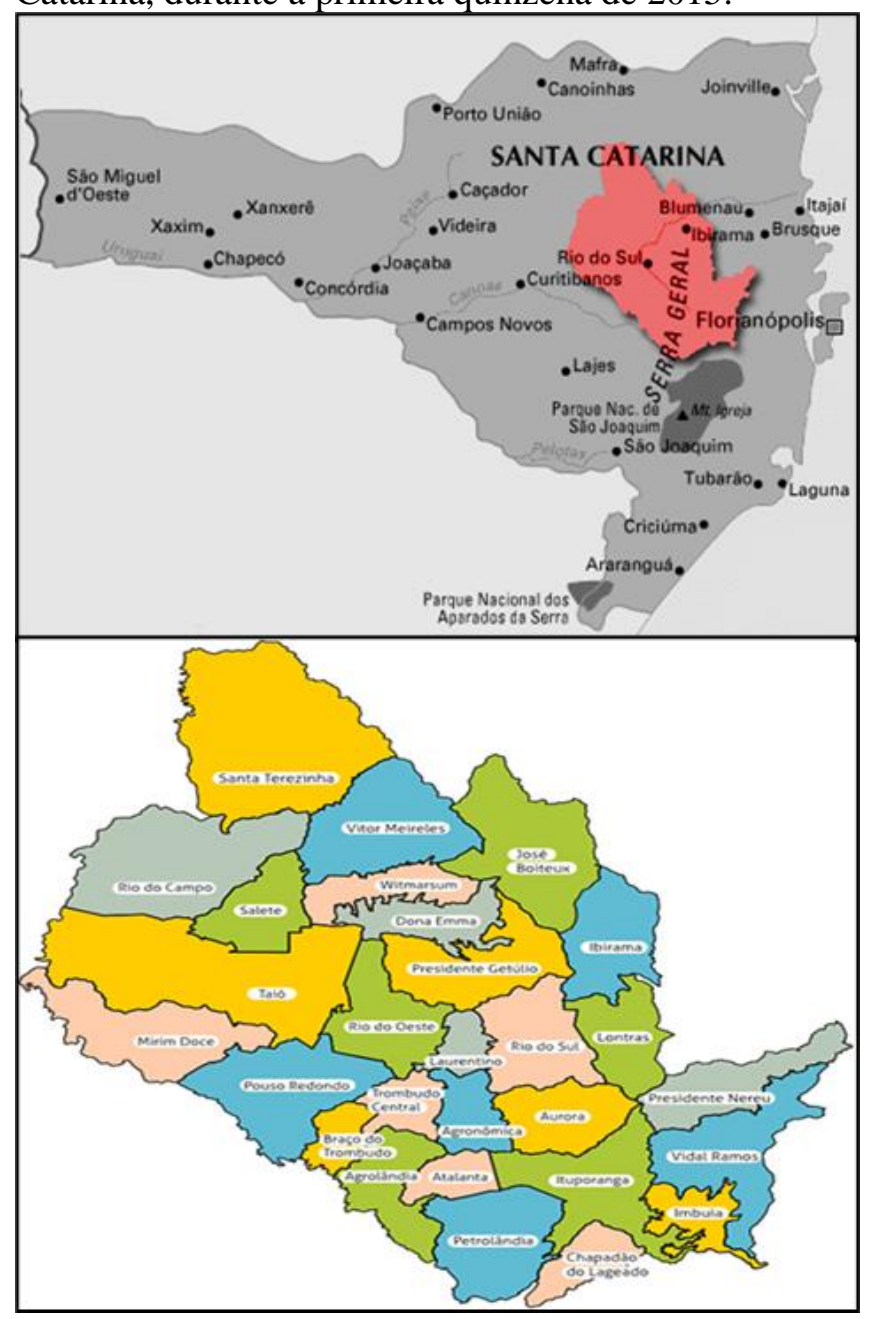

Figura 1 - Municípios de coleta de bulbos de cebola da região do Alto Vale do Itajaí, SC. Fonte: AMAVI (2020). 
Foram coletadas amostras de bulbos, informações de adubação de plantio e coberturas originadas de 27 produtores da safra 2014/2015, sendo 19 amostras da cv. Bola Precoce e oito da cv. Crioula. As amostras de bulbos visivelmente livres de infecções e injúrias foram coletadas aleatoriamente a uma profundidade de até 20 $\mathrm{cm}$, em três seções do armazém da propriedade, onde estavam armazenados a granel, em estaleiros ou bins (caixas com aproximadamente $500 \mathrm{~kg}$ de cebola). Nas propriedades, onde estavam armazenadas em sacos foram coletadas de três sacos aleatoriamente em seções diferentes, divididas proporcionalmente ao total armazenado. Entre os produtores, o total armazenado variou de 20 a 350 toneladas. As amostras de cada seção foram compostas de 18 bulbos (nove da classe 3 e nove da classe 4), totalizando 54 bulbos para cada produtor.

Para a realização do experimento em delineamento inteiramente casualizados, as amostras foram armazenadas individualizadas dentro de caixas plásticas vazadas em ambiente com ventilação natural por 140 dias. A armazenagem foi realizada no armazém da Estação Experimental da Epagri de Ituporanga - SC, localizado $\left(27^{\circ} 25^{\prime} 07^{\prime \prime} \mathrm{S}\right.$; $49^{\circ} 38^{\prime} 46^{\prime \prime} \mathrm{W}, 484 \mathrm{~m}$ de altitude), e avaliadas durante o período de 27 de janeiro a 16 de junho/2015. As médias internas ao armazém era em torno de $19,5^{\circ} \mathrm{C}$ para a temperatura e umidade relativa do ar $88,9 \%$.

As variáveis representadas por: $(\mathrm{CV})$ cultivares (1Bola Precoce e 2- Crioula); (CLA) Classes (3 e 4), a composição mineral do bulbo: $(\mathrm{CN})$ para Nitrogênio; (CP) para Fósforo; (CK) para Potássio; (CCa) para Cálcio; $(\mathrm{CMg})$ para Magnésio; $(\mathrm{CFe})$ para Ferro; $(\mathrm{CCu})$ para Cobre; (CZn) para Zinco; (CMn) para Manganês; (SST) para Sólidos Solúveis Totais; (ATT) para Acidez Total Titulável, para adubação no plantio:(NP) para Nitrogênio; (PP) para Fósforo; (KP) para Potássio, para adubação em Cobertura com: (NC) Nitrogênio; (KC) Potássio,para perdas por: (DES) Desidratação; (POD) Podridão e (BRO) Brotadas.

Os bulbos foram avaliados a cada 28 dias e calculadas as perdas de massa fresca (desidratação), bulbos apodrecidos e bulbos brotados, sendo os bulbos podres e brotados, identificados e pesados, posteriormente, excluídos da amostra. Foram obtidas as porcentagens das perdas acumuladas por amostra, obtendo assim, a perda final por amostra para os 140 dias de armazenagem. Para o cálculo da porcentagem das perdas por base da amostra, ocorreu no início do período de armazenagem. A partir das perdas acumuladas foi calculada a média das três amostras de cada repetição, ou seja, as médias de cada produtor às perdas por desidratação, apodrecimento e brotação. As cebolas quando apodreciam normalmente perdiam fluido pelo pseudocaule e ao efetuar a pesagem dos bulbos podres, esse suco não estava neles, proporcionando a diferença computada à desidratação, já que do peso inicial foi descontada dos apodrecidos e brotados. Desse modo, essa diferença ocorrida, pode-se levar para os resultados, uma pequena redução da perda por apodrecimento em detrimento a igual majoração na perda por desidratação, ainda para o bulbo que estava podre e brotado, foi computado como podre.

Ao final do período de 140 dias de armazenagem, três bulbos por amostra foram utilizados para determinação dos componentes minerais: Nitrogênio $(\mathrm{N})$; Fósforo (P); Potássio (K); Cálcio (Ca); Magnésio $(\mathrm{Mg})$; Ferro $(\mathrm{Fe})$; Zinco $(\mathrm{Zn})$; Cobre $(\mathrm{Cu})$; e Manganês (Mn). As análises de 27 amostras foram realizadas no laboratório do departamento de Solos da Universidade Federal do Paraná- UFPR. Nas análises de macro e micronutrientes ( $\mathrm{P}, \mathrm{K}, \mathrm{Ca}, \mathrm{Mg} \mathrm{Fe}, \mathrm{Cu}, \mathrm{Zn}, \mathrm{Mn}$ ), foi utilizada a metodologia de digestão via seca (mufla) e quantificação das amostras pelo equipamento ICP-OES. $\mathrm{A}$ análise do Nitrogênio $(\mathrm{N})$ foi realizada pela metodologia de combustão via seca pelo equipamento Analisador Elementar.

A determinação dos SST foi realizada por refratometria segundo o método 983.17 da AOAC (2005). Para os bulbos divididos ao meio na seção equatorial, coletou-se o exsudado das seções e determinado em refratômetro manual previamente calibrado com água destilada e os resultados expressos em ${ }^{\circ}$ Brix.

A determinação da ATT foi realizada por método de volumetria 942.15 da AOAC (2005) modificado. Foram pesados $10 \mathrm{~g}$ da matéria fresca, coletada no disco central dos bulbos, juntamente com $100 \mathrm{~mL}$ de água destilada e trituradas num liquidificador durante três minutos. Titulou-se com NaOH 0,1 mol L-1 até pH 8,2 em titulador com presença de solução de fenolftaleína, considerando que todo o ácido pirúvico, ácido orgânico predominante em cebolas, tenha sido titulado. A acidez da solução determinada é expressa em miliequivalentes de ácido pirúvico por $\mathrm{kg}$ de matéria fresca (MUNIZ et al., 2012).

A partir das respostas referentes a quantidade de adubação no plantio para adubação em cobertura. Das perdas calculadas e das análises da composição química dos bulbos, foram definidas vinte e uma variáveis.

Os resultados obtidos foram submetidos à análise de Correlação de Pearson Bivariada. As correlações obtidas entre as variáveis foram comparadas pelo teste de " $t$ "ao nível de $1 \%$ de probabilidade. Os coeficientes de correlação foram considerados qualitativamente como correlação fraca para valores modulados entre 0,00 e 0,30 , correlação moderada para valores de 0,30 até menores que 0,60 , para valores de 0,60 até menores que 0,90 como forte correlação e de 0,90 até menor que 1,00 correlação linear muito forte (CALLEGARIJACQUES, 2003). Foi utilizado o programa estatístico 
SPSS $^{\circledR}$-IBM ${ }^{\circledR}$ Statistics (IBM, 2012) para o cálculo e testes estatísticos.

\section{Resultados e Discussão}

As variáveis de adubação no plantio $(\mathrm{N}, \mathrm{P}, \mathrm{K})$ e cobertura $(\mathrm{N})$ apresentaram correlação significativa e positiva entre si, enquanto o potássio em cobertura não demonstrou correlação significativa entre as adubações (Tabela 1). Demonstrando que os produtores variam as quantidades de adubos no plantio de forma proporcional entre os tipos de fertilizantes, utilizando fórmulas indicadas para a cultura, mudando apenas a quantidade aplicada por área na expectativa de melhorar a produção/produtividade, e para o potássio em cobertura de acordo com as condições de clima.

A Acidez Total ao final do período de armazenagem não foi influenciada de forma significativa pelas quantidades de adubos aplicados no plantio ou em cobertura, no entanto, com as cultivares estudadas apresentou correlação moderada $(0,30)$ e significativa (5\%) sendo maior para a cv. Crioula, confirmando a observação popular que a "Crioula é mais picante" e de acordo com Chagas (2004), a cebola Crioula apresentou maior acidez entre outras cultivares (Pira Ouro, Baia Periforme, Granex 33, Jubileu e Texas Grano 502) e o brotamento também foi maior para a cultivar Crioula, ainda a ATT apresentou correlação fraca $(0,29)$ e positiva com a perda por brotação (Tabela 1), indicando que bulbos mais ácidos estão mais sujeitos a quebra de dormência e consequente brotação, isso fica confirmado quando a perda por brotação apresenta correlação moderada $(0,36)$ e maior para a cv. Crioula. A diferença apresentada na acidez titulável média na composição do bulbo entre as cultivares, foi para Crioula 3,60\% e Bola Precoce 3,38\% (Tabela 2), ainda a cv. Crioula tende a diminuir o conteúdo de $\mathrm{N}, \mathrm{P}, \mathrm{K}, \mathrm{Ca}, \mathrm{Mg}, \mathrm{Fe}$ e $\mathrm{Cu}$ em relação a Bola Precoce.

Para as variáveis da composição mineral dos bulbos, com exceção para o teor de Ca que não apresentou correlação significativa com nenhuma variável o restante dos componentes minerais $(\mathrm{N}, \mathrm{P}, \mathrm{K}, \mathrm{Mg}, \mathrm{Fe}$, $\mathrm{Cu}, \mathrm{Zn}$ e $\mathrm{Mn}$ ) apresentaram correlação positiva entre eles (Tabela 1).

Jayamohanrao (1974) verificou que as doses $13,4 \mathrm{~kg}$ $\mathrm{ha}^{-1}$ de $\mathrm{Cu}$ e de $1,8 \mathrm{~kg} \mathrm{ha}^{-1}$ de B melhoraram a composição mineral dos bulbos, principalmente o teor de $\mathrm{Ca}$, de $\mathrm{P}$ e de $\mathrm{Fe}$, neste trabalho apesar de não ter sido avaliado o volume de adubação $\operatorname{com~} \mathrm{Cu}$, mas considerando o resultado podemos afirmar que menor concentração de $\mathrm{Cu}$ no bulbo também diminui a concentração de $\mathrm{N}, \mathrm{P}, \mathrm{K}, \mathrm{Mg}, \mathrm{Fe}$ e $\mathrm{Mn}$ de forma significativa (1\%) e Mn (5\%), todos estes componentes se apresentaram em menores quantidades na cv. Crioula em relação a cv. Bola Precoce, conforme a Tabela 2.
Tabela 1 - Correlação de Pearson para composição, perdas e adubações dos bulbos das cultivares bola precoce e crioula para as classes 3 e 4 . Epagri/Ituporanga, 2015

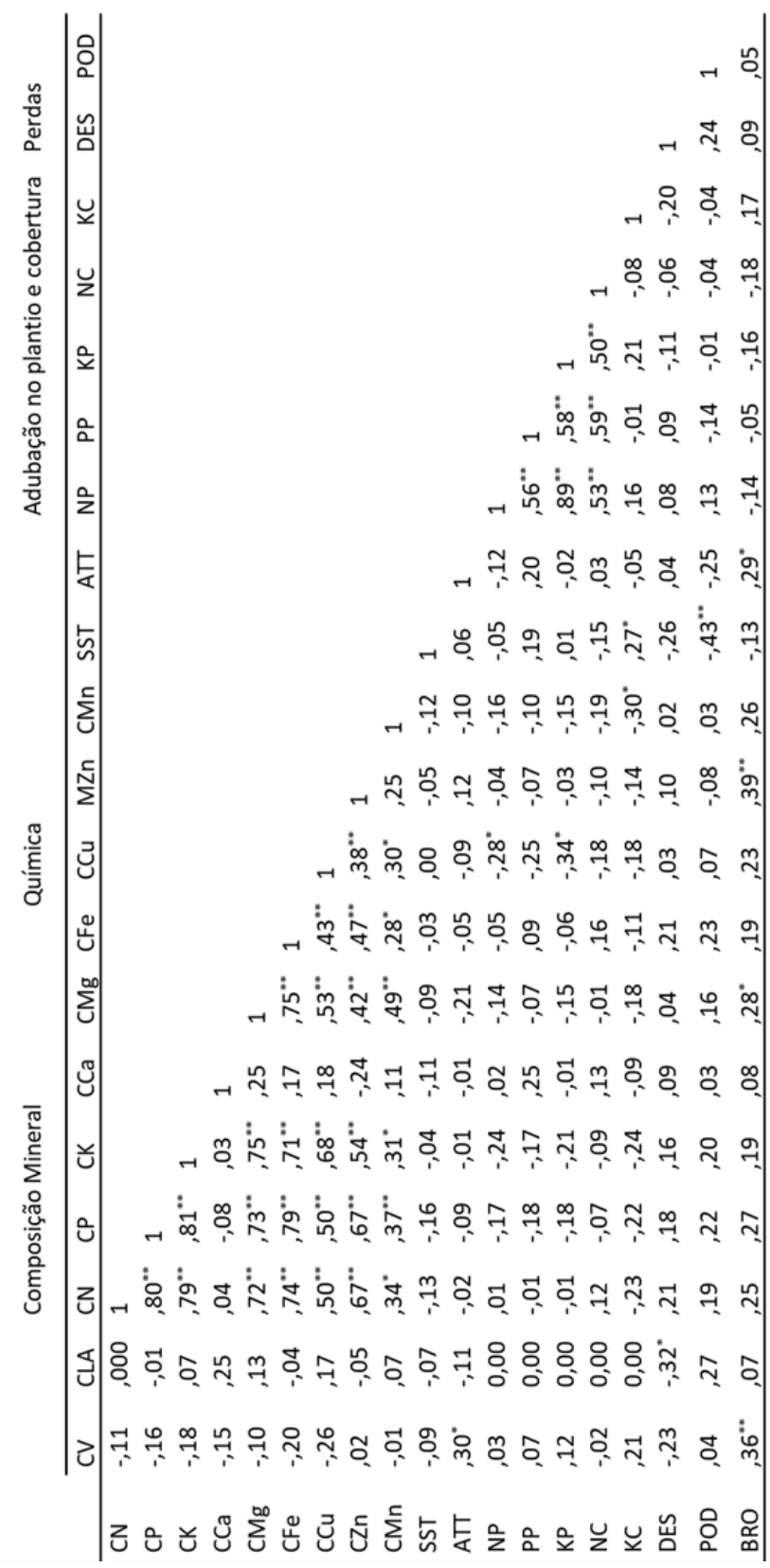

** A correlação é significativa no nível 0,01 . *A correlação é significativa no nível 0,05. LEGENDA: (CV) Cultivar; (CLA) Classe. Composição Mineral Teor de: (CN) Nitrogênio; (CP) Fósforo; (CCa) Cálcio; $(\mathrm{CMg})$ Magnésio; $(\mathrm{CFe})$ Ferro; $(\mathrm{CCu})$ Cobre; $(\mathrm{CZn})$ Zinco; (CMn) Manganês; (SST) Sólidos Solúveis Totais; (ATT) Acidez Total Tituláve. Adubação de plantio com: (NP) Nitrogênio; (PP) Fósforo; (KP) Potássio. Adubação em Cobertura com: (NC) Nitrogênio; (KC) Potássio.Perdas por: (DES) Desidratação; (POD) Podridão e (BRO) Brotadas. 
Tabela 2 - Médias dos constituintes minerais e químicos dos bulbos das cultivares bola precoce e crioula para as classes 3 e 4. Epagri/Ituporanga, 2015

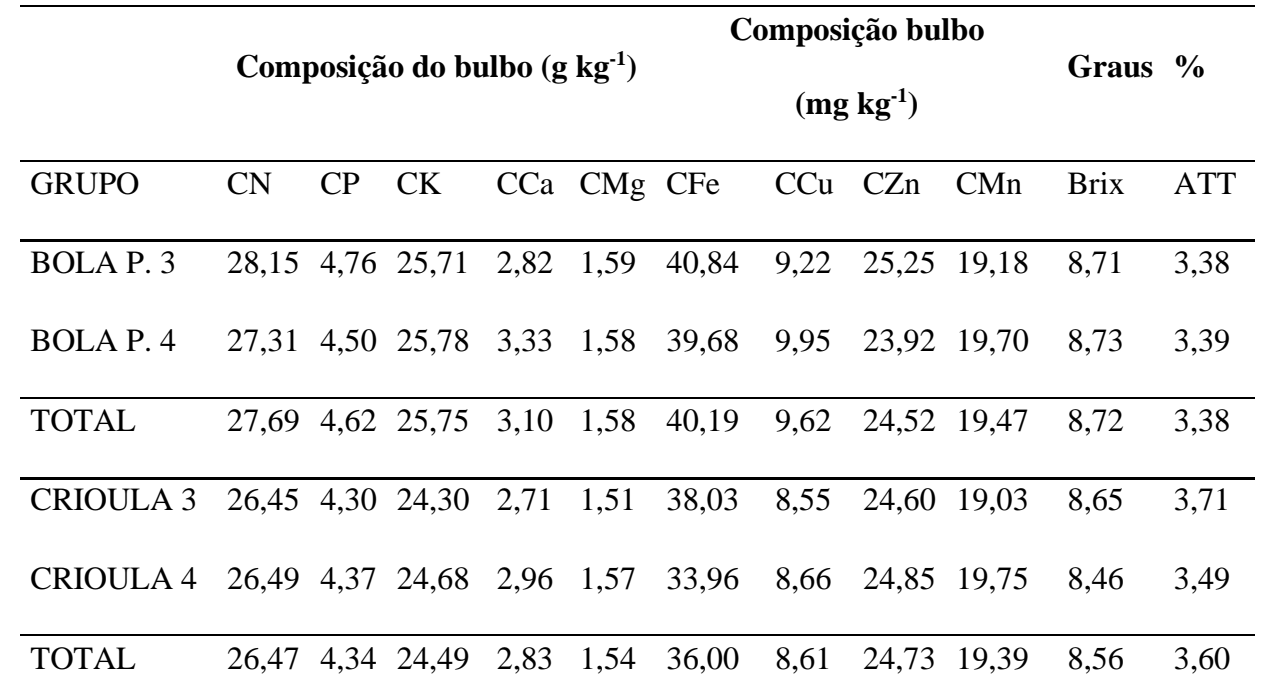

Composição Mineral - Teor de: (CN) Nitrogênio; (CP) Fósforo; (CCa) Cálcio; (CMg) Magnésio; (CFe) Ferro; $(\mathrm{CCu})$ Cobre; (CZn) Zinco; (CMn) Manganês; (SST) Sólidos Solúveis Totais; (ATT) Acidez Total Titulável.

Quanto ao brotamento os resultados apresentados indicam correlação moderada positiva e significativa (1\%) entre as perdas por brotamento com a cultivar $(0,36)$ medida maior para a cv. Crioula, que apresentou menores concentrações de $\mathrm{N}, \mathrm{P}, \mathrm{K}, \mathrm{Mg}, \mathrm{Fe}$ e $\mathrm{Mn}$ em relação a cv. Bola Precoce. Ainda o brotamento com o teor de Zinco correlação moderada $(0,39)$ e significativa $(5 \%)$, bem como, com Mg fraca $(0,28)$ e com a ATT fraca $(0,29)$, indicando que o aumento destes favorecem ao brotamento (Tabela 1). Possivelmente, o $\mathrm{Zn}$ que afeta a enzima frutose 1,6 difosfato que regula a quebra dos açúcares no citoplasma, fazendo com que a atividade destas enzimas seja reduzida pela deficiência de Zn, de forma que o seu aumento leva a uma maior degradação dos amidos e açúcares e também afeta a síntese e conservação das auxinas (MENDES et al., 2008). O modo como o $\mathrm{Zn}$ funciona no metabolismo das auxinas, principalmente do Ácido Indol Acético (AIA), ainda não está completamente claro, mas parece provável que a síntese de triptofano requer $\mathrm{Zn}$. O triptofano é o precursor numa rota da biossíntese de AIA (TAIZ; ZEIGER, 2013; KIRKBY; RÖMHELD, 2007). O Zn é requerido na rota da síntese do triptofano à auxina via triptamina, amina biogênica, formada a partir da descarboxilação do Trp (MALTA et al., 2002).

O Magnésio também é ativador de enzimas do processo de respiração, síntese de compostos orgânicos (AGEITEC, 2017), em especial, as descarboxilases e desidrogenases envolvidas no ciclo de Krebs (TAIZ; ZEIGER, 2013). Desta forma, as condições se apresentam favoráveis para o brotamento, maior presença de Zn, acelerando a degradação de carboidratos. O Mg favorece o processo de respiração e, por consequência, o aumento da acidez que na cebola, aumentando a disponibilidade de ácido pirúvico. $\mathrm{O}$ piruvato e o triptofano são precursores da síntese do AIA, o qual é um importante hormônio de crescimento, sendo também um potente ativador de enzimas, estimulando a germinação do bulbo. Deste modo, cuidados com excesso de adubação com Zn devem ser considerados, e feitos com aplicação ao solo uma vez que a aplicação de $\mathrm{Zn}$ nas folhas não alterou a produtividade de cebola (KURTZ; ERNANI, 2010).

Em relação à desidratação, apesar de não significativa a perda de massa fresca (desidratação), também tem correlação fraca negativa $(-0,26)$ com SST (Tabela 1), indicando equilíbrio entre SST e a quantidade de água livre no bulbo, onde maior teor de SST reduz a Aa (atividade da água) no bulbo como reduz também a evaporação, devido a menor disponibilidade de água e consequente menor perda de peso por desidratação, que é explicado pela relação $\mathrm{UR} \%=\mathrm{Aa} * 100$ (FRANCO; LANDGRAF, 2004), onde com a redução da Aa é necessária o menor UR\% para migrar água do bulbo para o ambiente.

Para a variável perda por desidratação, a correlação foi moderada $(-0,32)$ e significativa $(5 \%)$ com a classe comercial, demonstrando-se ser menor na classe 4 no que tange à relação a classe 3 (Tabela 1), contrariando resultados de outros trabalhos que indicam maiores perdas nas classes maiores, no entanto, isso pode ter acontecido em parte, em razão, a metodologia utilizada para identificar a desidratação e cebolas podres.

Resende, Costa e Alvarenga (2005) após cura evidenciaram maiores perdas de peso de massa fresca com o aumento médio de massa por bulbo, no entanto, 
quando consideramos perda de massa fresca como a soma da desidratação e apodrecimento parte deste resultado passa a ser verdadeiro. Somando as duas perdas, obtivemos respectivamente para $\mathrm{cv}$. Bola precoce e cv. Crioula; as perdas na classe 3 de $(9,16+$ $9,65) 18,81 \%$; $(8,19+12,52) 20,71 \%$ e na classe 4 de $21,79 \%(8,07+13,72) ;(7,60+12,49) 20,09 \%$, de acordo com a Tabela 3, observou-se que a classe 4 da cv. Bola precoce apresentou-se a soma destas perdas maiores de 2,98\% que na classe 3, já para a cv. Crioula apresentou-se ao contrário $0,62 \%$ maior para classe 3 .

Tabela 3 - Médias das quantidades de adubos aplicados no plantio e em cobertura e das perdas por desidratação, podridão, brotamento e soma das três perdas em 140 dias de armazenagem das cultivares bola precoce e crioula para as classes 3 e 4. Epagri/Ituporanga, 2015

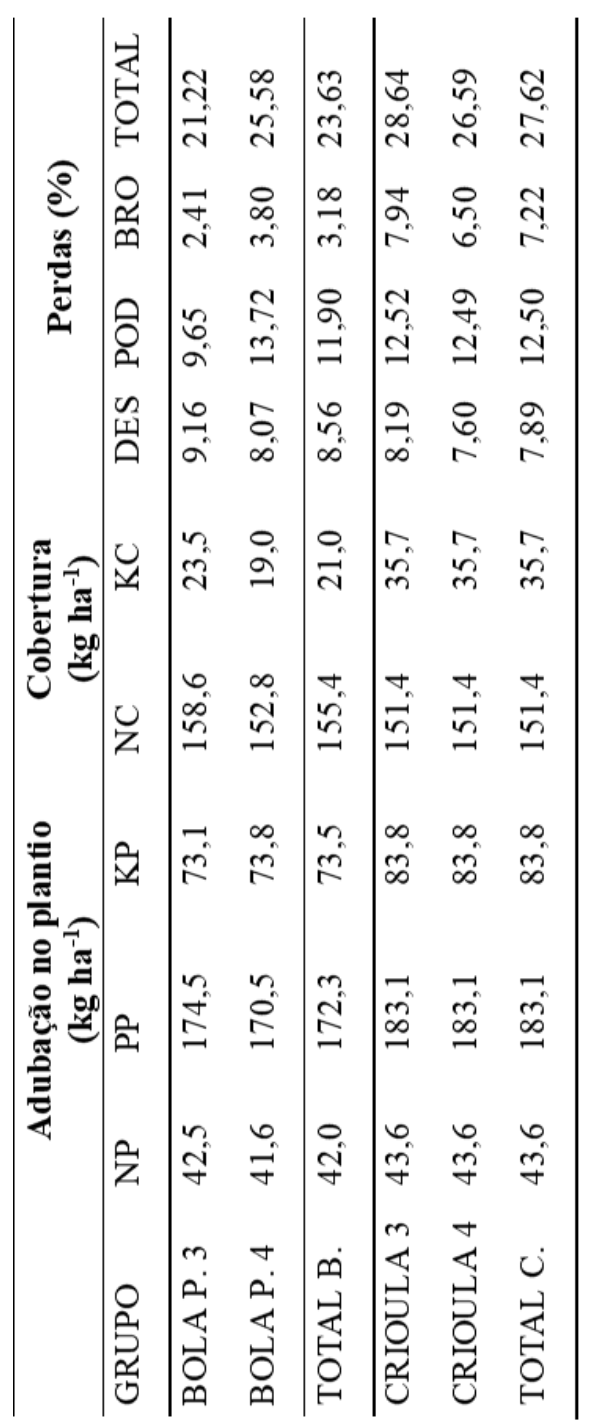

Legenda: Adubação de plantio com: (NP) Nitrogênio; (PP) Fósforo; (KP) Potássio. Adubação em Cobertura com: (NC) Nitrogênio; (KC) Potássio. Perdas por (DES) Desidratação; (POD) Podridão e (BRO) Brotadas.
Quando as podridões de bulbo, a perda apresentou correlação moderada e negativa com SST $(-0,43)$, indicando que um menor teor de SST favorece ao desenvolvimento de doenças nos bulbos (Tabela 1). Os valores médios obtidos para SST da cv. Bola Precoce foi de $8,72{ }^{\circ}$ Brix e para cv. Crioula de $8,56{ }^{\circ}$ Brix (Tabela 2). Segundo Carvalho (1980), o teor de sólidos totais em cebolas varia de 5 a $20 \%$. A correlação positiva fraca $(0,27)$ apresentada entre as adubações com potássio em cobertura significativa $(5 \%)$ e o teor de SST e negativa moderada com o teor de manganês (0,30 ), indica que o aumento de potássio em cobertura apesar de aumentar SST não foi significativo para a redução de bulbos apodrecidos (Tabela 1). Alto teor de sólidos totais está ligado à boa qualidade de armazenamento dos bulbos e melhora a resistência da cebola ao ataque microbiológico que causa a podridão no bulbo.

Para Resende e Costa (2008), a variedade 'Texas Grano', demonstrou interação significativa entre aumento das doses de $\mathrm{K}_{2} \mathrm{O}$, com redução da perda de massa em pós colheita, isto seria devido ao aumento do teor de sólidos solúveis ( ${ }^{\circ}$ Brix), com consequente, o maior teor de matéria seca que promove melhor conservação pós-colheita.

Nesse prisma, Resende e Costa (2009), estudando a interação em doses de potássio e nitrogênio, indicam evidências de redução significativa da perda de massa fresca com o incremento de adubação potássica que produzem bulbos com maior teor de SST ao contrário do resultado apresentado com o incremento de adubação nitrogenada que produzem bulbos 'mais aguados' e mais susceptíveis ao ataque microbiológico. O aumento de sólidos solúveis está relacionado com a redução da Aa no bulbo. A redução da Aa dificulta ao desenvolvimento de microrganismos nos bulbos, uma vez que, os bulbos necessitam de água livre para seus processos metabólicos, consequentemente, o crescimento e a multiplicação. $\mathrm{O}$ apodrecimento demonstrou ser maior para a classe 4 , apesar de não ser significativa $(0,27)$ (Tabela 1$)$ chegou próxima e provavelmente seria se as perdas de fluidos dos bulbos apodrecidos fossem computadas para esta perda.

Não ficou devidamente esclarecido o motivo pelo qual, o maior volume de potássio em cobertura reduz perda por desidratação, mas maior teor de potássio na composição do bulbo, apesar de não significativas (5\%), apresenta correlação $(0,16 ; 0,20 ; 0,19)$ positiva para as perdas por desidratação, apodrecimento e brotação respectivamente (Tabela 1 ).

\section{Considerações finais}

A cv. Crioula é mais sujeita ao brotamento que a cultivar Bola Precoce e o brotamento é mais intenso quanto mais ácida for a cebola. 
$\mathrm{O}$ aumento do teor de $\mathrm{Zn}$ no bulbo favorece ao brotamento, desta forma, cuidados com excesso de adubação com este nutriente devem ser considerados para evitar maiores perdas em armazenagem por mais de 90 dias.

A adubação de cobertura com potássio interfere de forma positiva no teor de Sólidos Solúveis Totais e negativa ao teor de manganês na composição.

As três perdas têm correlação negativa com Sólidos Solúveis Totais. O teor de K no bulbo tem correlação positiva fraca com as três perdas.

\section{Referências}

AGÊNCIA EMBRAPA DE INFORMAÇÃO TECNOLÓGICA (AGEITEC). Cultivo de cebola no Nordeste: sistemas de produção. 2017. Disponível em <http://www.cpatsa.embrapa.br:8080/sistema_produca o/spcebola/adubacao.htm>. Acesso em: 18 mai. 2020.

AMAVI - Associação dos Municípios do Alto Vale do Itajaí. Localização e distâncias. Disponível em: https://www.amavi.org.br/municipios-

associados/localizacao. Acesso em: 17mar 2021.

AOAC. Association of Official Analytical Chemist. Official Methods of Analysis. Arlington, 2005.

BOEING, G. Fatores que afetam a qualidade da cebola na agricultura familiar catarinense. Florianópolis: Instituto Cepa/SC, 2002.

CALLEGARI-JACQUES, S.M. Bioestatística: princípios e aplicações. Artmed, Porto Alegre, RS. 2003.

CARVALHO, V. D. Características nutricionais, industriais e terapêuticas da cebola. Informe Agropecuário, v 6, n.62, p.71-78, 1980.

CHAGAS, S. J. R.; RESENDE, G. M.; PEREIRA, L. V. Características qualitativas de cultivares de cebola no sul de Minas Gerais. Ciências Agrotécnicas, v.28, n.1, p.102-106, 2004.

CHAVES, L. H. G.; PEREIRA, H. H. G. Nutrição e adubação de tubérculos. Campinas: Fundação Cargill. 1985.

CHITARRA, M.IF.; CHITARRA, A.B. Pós-colheita de frutos e hortaliças: fisiologia e manuseio. Lavras: ESAL/FAEPE, 1990.
FRANCO, B. D. G. M.; LANDGRAF, M. Microbiologia dos Alimentos. Atheneu: São Paulo, 2004.

IBM. SPSS Statistics 21. IBM. 2012. Software. Disponível em: <http://www01.ibm.com/software/analytics/spss/products/statistics/ >. Acesso em: 21 dez. 2015.

JAYMOHANRAO, V. Effect of copper and boron on the mineral composition of onion (Allium cepa $\mathrm{L}$ ). Andhra Agricultural Journal. v.17, n.5, p.170-172. 1974.

KIRKBY, E. A.; RÖMHELD, V. Micronutrientes na fisiologia de plantas: micronutrientes na fisiologia de plantas: funções, absorção e mobilidade funções, absorção e mobilidade. International Plant Nutrition Institute. 2007. Informações agronômicas 118.

KURTZ, C.; ERNANI, P. R. Produtividade de cebola influenciada pela aplicação de micronutrientes. Revista Brasileira de Ciência do Solo, v.34, n.2, p.133-142, 2010.

LOUÉ, A. The interaction of potassium with other growth factors, particularly with other nutrients. In: Congress: Potassium Research-Review and Trends, v.11, p.407-434, 1978.

MALAVOLTA, E. Elementos de nutrição mineral de plantas. São Paulo:Ceres, 1980.

MALAVOLTA, E.; CROCOMO, O. J. O potássio e a planta. In: YAMADA, T.; IGUE, K.; MUZILLI, O.; USHERWOOD, N.R. Potássio na agricultura brasileira. Piracicaba: IPF/IIP. p.95-162.1982.

MALTA, M.R.; FURTINI NETO, A.E.; ALVES, J.D.; GUIMARÃES, P.T.G. Efeito da aplicação de zinco via foliar na síntese de triptofano, aminoácidos e proteínas solúveis em mudas de cafeeiro. Brazilian Journal of Plant Physiology, v.14, n.1, p.31-37, 2002.

MENDES, A. M. S.; FARIA, C. M. B.; SILVA, D. J.; RESENDE, G. M.; OLIVEIRA NETO, M. B.; SILVA, M. S. L.; Nutrição Mineral e Adubação da Cultura da Cebola no Submédio do Vale do São Francisco. Embrapa, Petrolina, 2008. Circular Técnica 86.

MORETTI, C. L.; DURIGAN, J. F. Processamento de cebola. Informe Agropecuário, Belo Horizonte, v.32, n.2, p.99-104, 2002. 
MUNIZ, L. B.; MORETTI, C. L.; MATTOS, L. M., CARVALHO, P. G. B.; MELO, C. O. Caracterização física e química de duas cultivares de cebola armazenadas sob refrigeração. Revista de Ciências Agrárias, v.35, n.1, p.261-273, 2012.

RESENDE, G. M.; COSTA, N. D.; ALVARENGA, M. A. R. Rendimento e perda de peso de bulbos de cebola cv. Texas grano $502 \mathrm{ppr}$ em diferentes espaçamentos de plantio. Caatinga, v. 18, n.1, p.28-34, 2005.

RESENDE, G. M.; COSTA, N. D. Épocas de plantio e doses de nitrogênio e potássio na produtividade e armazenamento da cebola. Pesquisa Agropecuária Brasileira, v.43, n.2, p.221-226, 2008.

Épocas de plantio e doses de nitrogênio e potássio na produtividade e armazenamento da cebola. Ciência Agrotécnica, v.33, n.5, p.1314-1320, 2009.

TAIZ, L.; ZEIGER, E. Fisiologia Vegetal. 5. ed. Porto Alegre: Artmed, 2013. 